\title{
Multiscale Comparative Evaluation of the GPM IMERG v5 and TRMM 3B42 v7 Precipitation Products from 2015 to 2017 over a Climate Transition Area of China
}

\author{
Cheng Chen ${ }^{2}$, Qiuwen Chen ${ }^{1,2}, *$, Zheng Duan ${ }^{3}{ }^{(0)}$, Jianyun Zhang ${ }^{1}$, Kangle $\mathrm{Mo}^{2}$, Zhe $\mathrm{Li}^{4}$ \\ and Guoqiang Tang ${ }^{5}$ \\ 1 State Key Laboratory of Hydrology-Water Resources and Hydraulic Engineering, Nanjing 210029, China; \\ jyzhang@nhri.cn \\ 2 Center for Eco-Environmental Research, Nanjing Hydraulic Research Institute, Nanjing 210029, China; \\ chencheng@nhri.cn (C.C.); klmo@nhri.cn (K.M.) \\ 3 Chair of Hydrology and River Basin Management, Technical University of Munich, Arcisstrasse 21, \\ 80333 Munich, Germany; duanzheng2008@gmail.com \\ 4 Key Laboratory of Water Cycle and Related Land Surface Processes, Institute of Geographic Sciences and \\ Natural Resources Research, Chinese Academy of Sciences, Beijing 100101, China; lizhe@igsnrr.ac.cn \\ 5 State Key Laboratory of Hydroscience and Engineering, Department of Hydraulic Engineering, \\ Tsinghua University, Beijing 100084, China; 15201514761@163.com \\ * Correspondence: qwchen@nhri.cn; Tel.: +86-25-85829765
}

Received: 16 May 2018; Accepted: 11 June 2018; Published: 14 June 2018

\begin{abstract}
The performance of the latest released Integrated Multi-satellitE Retrievals for GPM mission (IMERG) version 5 (IMERG v5) and the TRMM Multisatellite Precipitation Analysis 3B42 version 7 (3B42 v7) are evaluated and compared at multiple temporal scales over a semi-humid to humid climate transition area (Huaihe River basin) from 2015 to 2017. The impacts of rainfall rate, latitude and elevation on precipitation detection skills are also investigated. Results indicate that both satellite estimates showed a high Pearson correlation coefficient ( $r$, above 0.89$)$ with gauge observations, and an overestimation of precipitation at monthly and annual scales. Mean daily precipitation of IMERG v5 and 3B42 v7 display a consistent spatial pattern, and both characterize the observed precipitation distribution well, but 3B42 v7 tends to markedly overestimate precipitation over water bodies. Both satellite precipitation products overestimate rainfalls with intensity ranging from 0.5 to $25 \mathrm{~mm} /$ day, but tend to underestimate light $(0-0.5 \mathrm{~mm} /$ day) and heavy ( $>25 \mathrm{~mm} /$ day) rainfalls, especially for torrential rains (above $100 \mathrm{~mm} /$ day). Regarding each gauge station, the IMERG v5 has larger mean $r$ ( 0.36 for GPM, 0.33 for TRMM) and lower mean relative root mean square error (RRMSE, 1.73 for GPM, 1.88 for TRMM) than those of 3B42 v7. The higher probability of detection $(P O D)$, critical success index (CSI) and lower false alarm ratio (FAR) of IMERG v5 than those of $3 \mathrm{~B} 42 \mathrm{v} 7$ at different rainfall rates indicates that IMERG v5 in general performs better in detecting the observed precipitations. This study provides a better understanding of the spatiotemporal distribution of accuracy of IMERG v5 and 3B42 v7 precipitation and the influencing factors, which is of great significance to hydrological applications.
\end{abstract}

Keywords: GPM IMERG v5; TRMM 3B42 v7; precipitation; evaluation; Huaihe River basin

\section{Introduction}

Precipitation is a major force in global climate change, hydrological cycles, and ecological environments, which is of great importance to agricultural irrigation and disaster prevention [1-3]. 
Precipitation data at high spatiotemporal resolutions are essential for hydrological simulation at local, regional, and global scales [4] as the key component of the global water cycle. Conventional rain gauge observations at the basin scale are usually relatively sparse and are insufficient for accurately characterizing the spatial distribution of precipitation. In contrast, satellite remote sensing has the advantages of completely scanning the entire study region and convenient access to the data, providing an alternate way to monitor precipitation at regional and global scales.

More and more global precipitation datasets have been produced with the development of various spaceborne and related satellite-based precipitation retrieval algorithms, including the Precipitation Estimation from Remote Sensing Information using Artificial Neural Network (PERSIANN) [5], Climate Prediction Center Morphing (CMORPH) [6], Global Satellite Mapping of Precipitation (GSMaP) [7], Climate Hazards Group InfraRed Precipitation with Station data (CHIRPS) [8], TRMM Multisatellite Precipitation Analysis data (TMPA) [9], and Integrated Multi-satellitE Retrievals for GPM mission (IMERG) [10].

Building upon the success of TRMM, the GPM mission is expected to advance the understanding of Earth's water and energy cycle, improve forecasting of extreme rainfall events, and extend current capabilities for using accurate and timely information on precipitation to directly benefit society [10]. Compared with TRMM, GPM provides precipitation measurements at a higher spatial (from $0.1^{\circ}$ to $0.25^{\circ}$ ) and temporal (from half-hourly to 3-hourly) resolution. GPM offers orbital and gridded products at three different levels of data processing. The Level-3 product, the Integrated Multi-satellitE Retrievals for GPM (IMERG), combines GMI-DPR rainfall averages and rainfall estimates with data from all active and passive microwave instruments in the GPM constellation [11]. The IMERG product is available in three distinct modes- "Early Run" (latency: $\sim 6 \mathrm{~h}$ after observation time), "Late Run" (latency: $\sim 18 \mathrm{~h}$ ) and "Final Run" (latency: $\sim 4$ months), depending upon latency and application requirements. IMERG Final Run is not only the longest daily precipitation dataset among the IMERG products, but also incorporates monthly precipitation-gauge analyses, which provides more accurate results [12]. Recently, the assessment of the IMERG Day 1 Final Run product has been carried out in various regions of the world.

The earliest evaluation and comparison of GPM Day-1 IMERG version 4 (IMERG v4) and TRMM 3B42 v7 products was carried out over Mainland China from April to December 2014 at the hourly time scale at multiple spatiotemporal scales by Tang et al. [13]. The results showed that Day-1 IMERG v4 better captures the diurnal variability of precipitation, but both products have room for further improvement, particularly in the dry climate and high-latitude regions. Tang et al. [14] also conducted a comparison study of GPM IMERG v4 and TRMM 3B42 v7 with a dense gauge network over the mid-latitude Ganjiang River basin in southeast China from May to September 2014 (rainy season) using the Coupled Routing and Excess Storage (CREST) hydrologic model. It was shown that the daily IMERG v4 product could adequately substitute for the 3B42 v7 products both statistically and hydrologically. Ma et al. [15] analyzed the three-hourly rainfall estimates over the Tibetan Plateau in the warm season of 2014. It was found that both IMERG v4 and 3B42 v7 showed similar rainfall patterns and captured the northward dynamic life cycle of the Indian monsoon reasonably well, and that IMERG v4 showed the potential for detecting solid precipitation, which cannot be retrieved from the 3B42 v7 products. Gaonao et al. [16] evaluated the first full year (12 March 2014 to 1 April 2015) performance of IMERG v4 against radar rainfall fields at $30 \mathrm{~min}, 24 \mathrm{~h}$, monthly, and yearly durations above the land surface of the Netherlands, where the TRMM products were not available. Similar studies have also been carried out in India [17,18], Southern Canada [19] and Singapore [20].

GPM provides more detailed information on precipitation with higher spatial and temporal resolution than TRMM as a new generation of global precipitation observations. Since most gridded precipitation products have global (or quasi-global) coverage, their performance is expected to vary among regions [21,22]. To the authors' knowledge, studies of satellite precipitation in climatic transition zones still remain insufficient [23]. Sun et al. [24] had taken the Huaihe River basin, a typical semi-humid to humid climate transition area, as a study case to evaluate four satellite-gauge merged 
quantitative precipitation estimation products (TRMM 3B42 v7, CMORPH BLD, CMORPH CRT and CMORPH CMA) during 2003-2012 and further applied them in a distributed Variable Infiltration Capacity (VIC) model to assess their hydrologic applicability. Additionally, the current study still remains on the IMERG v4. The latest IMERG Final Run product version 5 (abbreviated as IMERG v5 hereafter), which has been available since March 2014, was released in November 2017. Compared with IMERG v4, the IMERG v5 data has made several important improvements [25]. The GPROF-TMI is not presently included in the IMERG Final datasets (version 5), for example. Therefore, evaluation of these precipitation products, especially the latest released GPM IMERG v5 precipitation product with reliable measurements in climatic transition zones, is an important topic, which is beneficial to both product developers and users.

This study assesses GPM-era and TRMM-era precipitation estimates/products (IMERG v5 and 3B42 v7) over a typical semi-humid to humid climate transition zone of China. The objectives are to (1) evaluate and compare the performance of IMERG v5 and 3B42 v7 precipitation products at multiple scales in the climatic transition basin (Huaihe River basin), (2) analyze the precipitation detection capability of 3B42 v7 and IMERG v5 satellite sensors at different rainfall rate thresholds, and (3) investigate the influence of local topographical features on precipitation retrievals. The study will contribute to quantitative assessment of the potential applicability of satellite precipitation products in hydrological prediction and disaster prevention in climatic transition regions.

\section{Materials and Methods}

\subsection{Study Area}

The Huaihe River basin is located in the east of China at latitude $30^{\circ} 55^{\prime} \mathrm{N}-36^{\circ} 36^{\prime} \mathrm{N}$ and longitude $111^{\circ} 55^{\prime} \mathrm{E}-121^{\circ} 25^{\prime} \mathrm{E}$ and is about halfway between the Yellow River and Yangtze River basins (Figure 1), with a total watershed area of $270,000 \mathrm{~km}^{2}$. It is in the middle of the North-South climatic transition zone of China, which belongs to a typical semi-humid to humid climate. It is surrounded on three sides by mountains, on the east by the sea, with vast plains in the middle. The plain area accounts for $75 \%$ of the watershed, and the mountains and hills are distributed in the west, southwest, and northeast. The Huaihe is the dividing line of the Huaihe River basin, and its northern and southern parts belong to the temperate monsoon climate area and subtropical monsoon climate, respectively. There are many tributaries and large lakes, such as Hongze Lake, Nansi Lake, Luoma Lake, and Gaoyou Lake, in the Huaihe River basin (Figure 1). Rainfall in the Huaihe River basin is relatively abundant but unevenly distributed as one of China's representative extreme rainstorm-prone areas. Generally, basin-scale average annual precipitation is about $920 \mathrm{~mm} /$ year, and precipitation is mainly concentrated during the rainy period from May to October. The basin has been suffering from frequent floods and droughts. Therefore, timely and accurate monitoring of the spatiotemporal distribution of regional rainfall plays an important role in hydrological and meteorological predictions and natural hazard alarms, especially in the climatic transition region. 


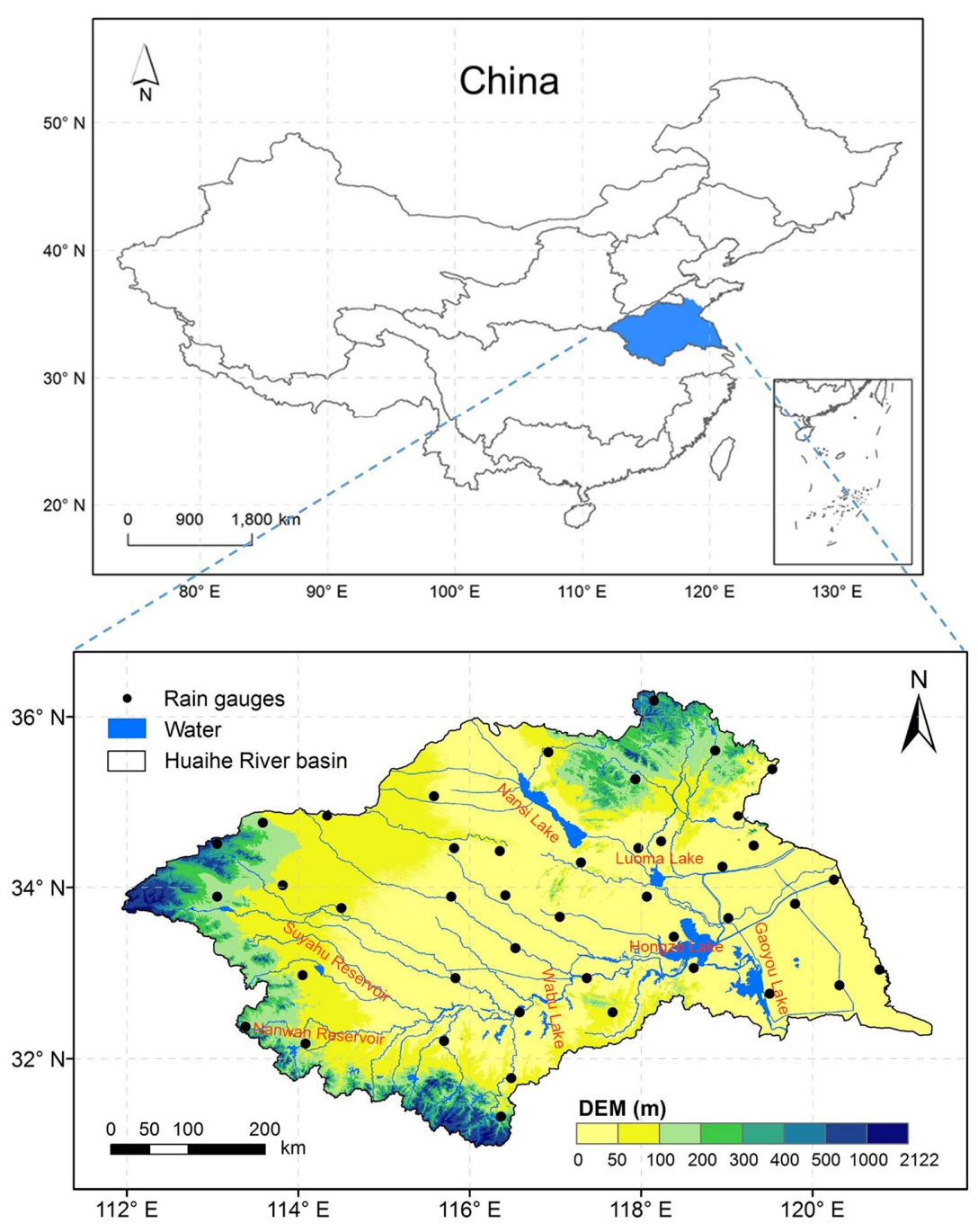

Figure 1. Geographical location, DEM and the distribution of rain gauges in the Huaihe River basin.

\subsection{Datasets and Preprocessing}

\subsubsection{TRMM 3B42 v7}

The Tropical Rainfall Measuring Mission (TRMM) launched on 27 November 1997 is a joint space mission between the National Aeronautics and Space Administration (NASA) and the Japanese Aerospace Exploration Agency (JAXA), which is designed to monitor and study tropical rainfall. The TRMM Multi-satellite Precipitation Analysis (TMPA) is one of the TRMM products designed to combine precipitation measurements from various satellite systems and precipitation gauges [9], which consist of two main products, the 3-hourly combined microwave-IR estimates (3B42) and monthly combined microwave-IR-gauge (3B43). The 3B42 precipitation estimates, which have a 3-hourly temporal resolution and a $0.25^{\circ}$ spatial resolution with spatial coverage extending from $50^{\circ} \mathrm{S}$ to $50^{\circ} \mathrm{N}$, have been widely used in hydrometeorological research during the past decade [11].

The version-7 post-real-time 3B42 (abbreviated as 3B42 v7) estimates from 2015 to 2017 were used, and the original 3-hourly data was accumulated to obtain daily precipitation. The 3B42 v7 data were downloaded from the Precipitation Measurement Missions (PMM) website (http://pmm.nasa.gov). Major changes were made to the algorithm to involve the radar reflectivity-rainfall rate relationship, surface clutter detection over high terrain, a new reference database for the passive microwave algorithm, and a higher-quality gauge analysis product for monthly bias correction with respect to its 
predecessor, Version $6[26,27]$. The $3 \mathrm{~B} 42 \mathrm{v} 7$ data were resampled to the same spatial resolution $\left(0.1^{\circ}\right)$ as IMERG v5 data by using the standard bilinear interpolation method $[15,28]$ to make them comparable. The 3B42 v7 daily precipitation data were accumulated to obtain the monthly and annual precipitation.

\subsubsection{GPM IMERG v5}

The Global Precipitation Measurement (GPM) Core Observatory initiated by NASA and JAXA was launched on 27 February 2014. GPM, which consists of a Ku/Ka-band Dual-frequency Precipitation Radar (DPR) and a multi-channel GPM Microwave Imager (GMI), is expected to provide the next-generation global observations of rain and snow and to improve weather and precipitation forecasts through assimilation of instantaneous precipitation information. The Integrated Multi-satellitE Retrievals for GPM (IMERG) is the Level 3 multi-satellite precipitation algorithm of GPM, which combines intermittent precipitation estimates from all constellation microwave sensors, IR-based observations from geosynchronous satellites, and monthly gauge precipitation data $[10,11]$. There are three different daily IMERG products, which are IMERG Day 1 Early Run (near real-time with a latency of $6 \mathrm{~h}$ ), IMERG Day 1 Late Run (reprocessed near real-time with a latency of $18 \mathrm{~h}$ ) and IMERG Day 1 Final Run (gauged-adjusted with a latency of four months) [29]. The IMERG Final Run product provides more accurate precipitation information than the near real-time products across GPCC-gauged regions [11].

The latest released GPM IMERG version 5 (IMERG v5) dataset is produced at NASA Goddard Earth Sciences (GES) Data and Information Services Center (DISC) by simply summing the valid precipitation retrievals for the day in GPM_3IMERGHH and giving the result in $\mathrm{mm}$. The IMERG precipitation products have a relatively finer spatial $\left(0.1^{\circ}\right.$ latitude/longitude) and temporal (half-hourly) resolution, with spatial coverage from $60^{\circ} \mathrm{S}$ to $60^{\circ} \mathrm{N}$. The calibrated IMERG Day 1 Final Run v5 data at daily scale over the Huaihe River basin from 2015 to 2017 were used in the current study, and the daily precipitation data were accumulated to obtain the monthly and annual precipitation. The GPM IMERG v5 data were also downloaded from the PMM website.

\subsubsection{Rain Gauge Data}

A dataset with daily rain gauge measurements in the Huaihe River basin from 2015 to 2017 was used as the ground reference for the evaluation of TRMM 3B42 v7 and GPM IMERG v5. The dataset contained the observations from 43 rain gauge stations of China's ground climatological data sheet (V3.0) (SURF_CLI_CHN_MUL_DAY_V3.0) and was provided by the China Meteorological Data Service Center (http://www.cma.gov.cn) [30,31]. The SURF_CLI_CHN_MUL_DAY_V3.0 dataset contains data from 824 benchmark and basic weather stations across the country, providing high quality information on precipitation since January 1951. All data were compiled by the National Meteorological Information Center and subjected to a series of quality controls, including examining extreme values and an internal consistency check, and removal of questionable data according to the methods described by $\mathrm{Xu}$ et al. [32]. The locations of the rain gauges are shown in Figure 1.

\subsubsection{DEM Data}

The Shuttle Radar Topography Mission Digital Elevation Model (SRTM DEM) data (http:/ / www. nasa.gov/) were used to analyze the impact of elevation on the spatial distribution of precipitation in this study. The original $90 \mathrm{~m}$ SRTM DEM data was resampled to $0.1^{\circ}$ spatial resolution to make it consistent with the evaluated satellite precipitation data.

\subsection{Methodologies}

To evaluate the performance of TRMM 3B42 $\mathrm{v} 7$ and GPM IMERG v5 precipitation products and ensure proper error analysis on a grid basis at multiple scales over the basin, the specified location or pixel for each rain gauge was checked, and then, the spatial-temporal coincident satellite pixel with corresponding gauges was evaluated $[15,20]$. Only the satellite grids that covered at least one rain 
gauge were evaluated, and the other grids with no rain gauges were excluded from the evaluation. There were no pixels with more than one rain gauge. The evaluation and comparison were also conducted at each individual gauge station, and the Thiessen polygon method was used to divide the basin into 43 polygons based on gauge stations. Additionally, the probability distribution function (PDF) and mean daily precipitation were calculated at different rainfall rates, and the impacts of latitude and elevation on precipitation were also assessed. It should be emphasized that the gauge observations at daily scale with no precipitation were excluded from this evaluation [15].

Several evaluation indicators were selected, including Pearson correlation coefficients $(r)$, relative bias $(R B)$, and relative root mean square error (RRMSE). The $r$ was used to quantify the type of correlation and dependence between satellite products and gauge observations in fundamental statistics. The RB and RRMSE were used to describe the bias and error of satellite precipitation compared with gauge observations [33-35]. The equations of the indicators are as follows:

$$
\begin{gathered}
r=\frac{\sum_{i=1}^{n}\left(P_{i}-\bar{P}\right)\left(G_{i}-\bar{G}\right)}{\sqrt{\sum_{i=1}^{n}\left(P_{i}-\bar{P}\right)^{2}} \sqrt{\sum_{i=1}^{n}\left(G_{i}-\bar{G}\right)^{2}}}, \\
R B=\frac{\sum_{i=1}^{n}\left(P_{i}-G_{i}\right)}{\sum_{i=1}^{n} G_{i}}, \\
\text { RRMSE }=\sqrt{\frac{\sum_{i=1}^{n}\left(P_{i}-G_{i}\right)^{2}}{n}} /\left(\frac{1}{n} \sum_{i=1}^{n} G_{i}\right),
\end{gathered}
$$

where $n$ represents the number of rain gauge stations; $P_{i}$ and $G_{i}$ represent satellite precipitation estimates and rain gauge observed precipitation $(\mathrm{mm})$, respectively; $\bar{P}$ and $\bar{G}$ represent mean satellite precipitation estimates and mean rain gauge observed precipitation $(\mathrm{mm})$, respectively.

The probability of detection (POD), false alarm ratio (FAR) and critical success index (CSI) were calculated at a daily time step to quantitatively examine the potential of satellite products for precipitation detection at different rainfall thresholds. The FAR gave the fraction of spurious events among all the events the satellites detected [36,37]. The POD indicated the fraction of precipitation events that were correctly detected, whereas the CSI denoted the number of correct forecasts of a rain event, divided by the total of hits, false alarms, and misses [38]. The $2 \times 2$ contingency table for each precipitation threshold is shown in Table 1 , where hits $(\mathrm{H})$ represent precipitation observed by the rain gauge and satellite simultaneously, false alarms (F) represent precipitation observed by the satellite but not observed by the rain gauge, misses $(\mathrm{M})$ represent precipitation observed by the rain gauge but not observed by the satellite, and correct negatives $(\mathrm{CN})$ represents precipitation observed neither by the rain gauge nor the satellite. Eight thresholds $(0.5,1,2,5,10,25,50,100 \mathrm{~mm} /$ day) were defined to identify the capability of 3B42 v7 and IMERG v5 precipitation data at different rainfall rates in this study. The POD, FAR, and CSI at each threshold were calculated by Equations (4)-(6), and the satellite precipitation data showed perfect agreement with rain gauge observations when $F A R=0, P O D=1$, and $C S I=1$.

$$
\begin{gathered}
P O D=\frac{H}{H+M^{\prime}} \\
F A R=\frac{F}{H+F^{\prime}} \\
C S I=\frac{H}{H+M+F^{\prime}}
\end{gathered}
$$


Table 1. The $2 \times 2$ contingency table summarizing the agreement between rain gauges $(\mathrm{G})$ and satellite precipitation products $(\mathrm{P})$ for each precipitation threshold.

\begin{tabular}{ccc}
\hline & G $\geq$ Threshold & G $<$ Threshold \\
\hline $\mathrm{P} \geq$ threshold & H (hits) & F (false alarms) \\
$\mathrm{P}<$ threshold & $\mathrm{M}$ (misses) & $\mathrm{CN}$ (correct negatives) \\
\hline
\end{tabular}

\section{Results}

\subsection{Spatiotemporal Assessment of IMERG v5 and 3B42 v7 Precipitation Estimates}

Figure 2a,c shows the scatterplots of TRMM 3B42 v7 and GPM IMERG v5 satellite precipitation products versus rain gauge data at daily, monthly, and annual scales from 2015 to 2017 over the Huaihe River basin, respectively. The evaluation metrics were also included in Figure 2. Both satellite precipitation products showed low accuracy at daily scale with small $r(0.314$ for 3B42 v7, 0.413 for IMERG v5). The values of $r$ significantly increased from daily scale to monthly scale (0.898 and 0.914 for 3B42 v7 and IMERG v5, respectively) and annual scale (0.896 and 0.939 for 3B42 v7 and IMERG v5, respectively). The RRMSE of the two satellite precipitation products was decreasing as the time scale increased. The positive values of $R B$ at monthly and annual scales indicated that satellite precipitation products tended to overestimate the gauge precipitation in the Huaihe River basin, while the negative values of $R B$ at daily scale indicated an underestimation. Compared with the 3B42 v7 data, the IMERG v5 data with larger $r$ and lower RRMSE had better performance.

Table 2 shows the evaluation results ( $r, R B$ and $R R M S E)$ of TRMM $0.25^{\circ}$, TRMM $0.1^{\circ}$, and GPM $0.1^{\circ}$ rainfall estimates at multiple timescales from 2015 to 2017 over the Huaihe River basin. TRMM $0.25^{\circ}$ means that the initial TRMM 3B42 v7 data $\left(0.25^{\circ}\right)$ was evaluated against the gauge stations, while TRMM $0.1^{\circ}$ means the interpolated TRMM 3B42 v7 data $\left(0.1^{\circ}\right)$ was used for the evaluation. It is seen in Table 2 that at daily scale, the evaluation results of TRMM $0.25^{\circ}$ were the worst with the smallest $r$ (0.259), the largest RRMSE (1.965), and largest absolute $R B(0.385)$. Regarding monthly and annual scales, the evaluation results of TRMM $0.25^{\circ}$ were slightly better than that of TRMM $0.1^{\circ}$. Overall, GPM IMERG data $\left(0.1^{\circ}\right)$ had the best performance. It must be noted that all the statistical analyses of TRMM data afterwards were based on the $0.1^{\circ}$ interpolated TRMM 3B42 v7 data to make it comparable with GPM IMERG v5 data.

Table 2. Evaluation results of TRMM $0.25^{\circ}$, TRMM $0.1^{\circ}$, and GPM $0.1^{\circ}$ precipitation estimates at multiple timescales from 2015 to 2017 over the Hauihe River basin.

\begin{tabular}{|c|c|c|c|c|}
\hline Time Scales & Satellite Products & $r$ & $R B$ & RRMSE \\
\hline \multirow{3}{*}{ Daily } & TRMM $0.25^{\circ}$ & 0.259 & -0.385 & 1.965 \\
\hline & TRMM $0.1^{\circ}$ & 0.314 & -0.273 & 1.897 \\
\hline & GPM $0.1^{\circ}$ & 0.413 & -0.176 & 1.753 \\
\hline \multirow{3}{*}{ Monthly } & TRMM $0.25^{\circ}$ & 0.904 & 0.059 & 0.442 \\
\hline & TRMM $0.1^{\circ}$ & 0.896 & 0.063 & 0.453 \\
\hline & GPM $0.1^{\circ}$ & 0.914 & 0.117 & 0.424 \\
\hline \multirow{3}{*}{ Annual } & TRMM $0.25^{\circ}$ & 0.901 & 0.059 & 0.141 \\
\hline & TRMM $0.1^{\circ}$ & 0.896 & 0.063 & 0.148 \\
\hline & GPM $0.1^{\circ}$ & 0.939 & 0.117 & 0.156 \\
\hline
\end{tabular}



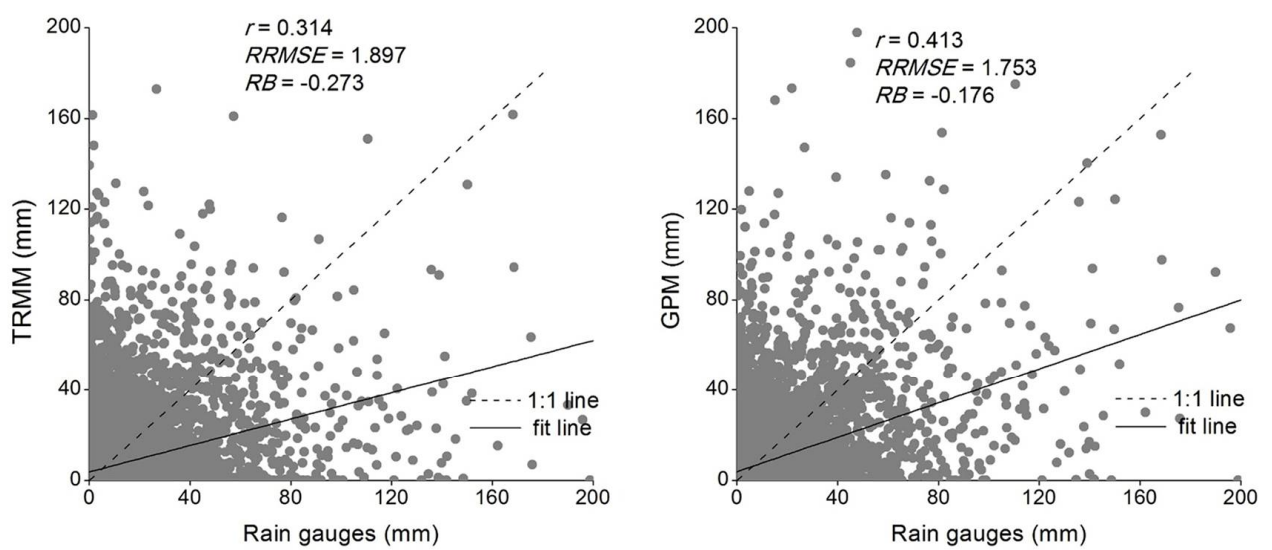

(a) Daily
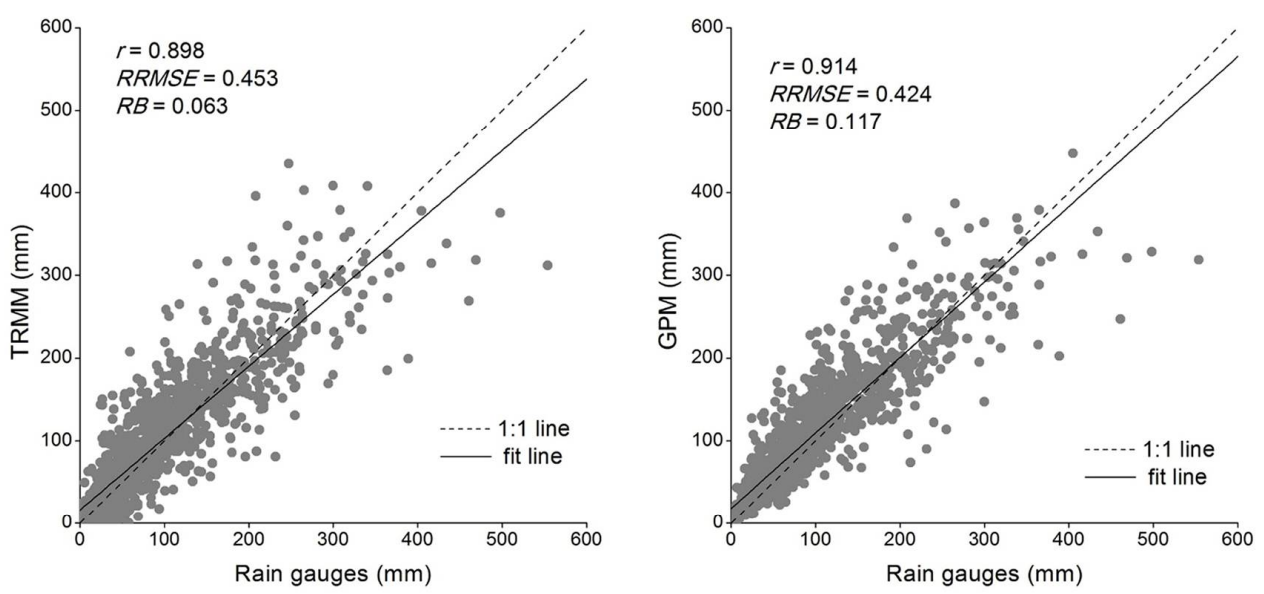

(b) Monthly
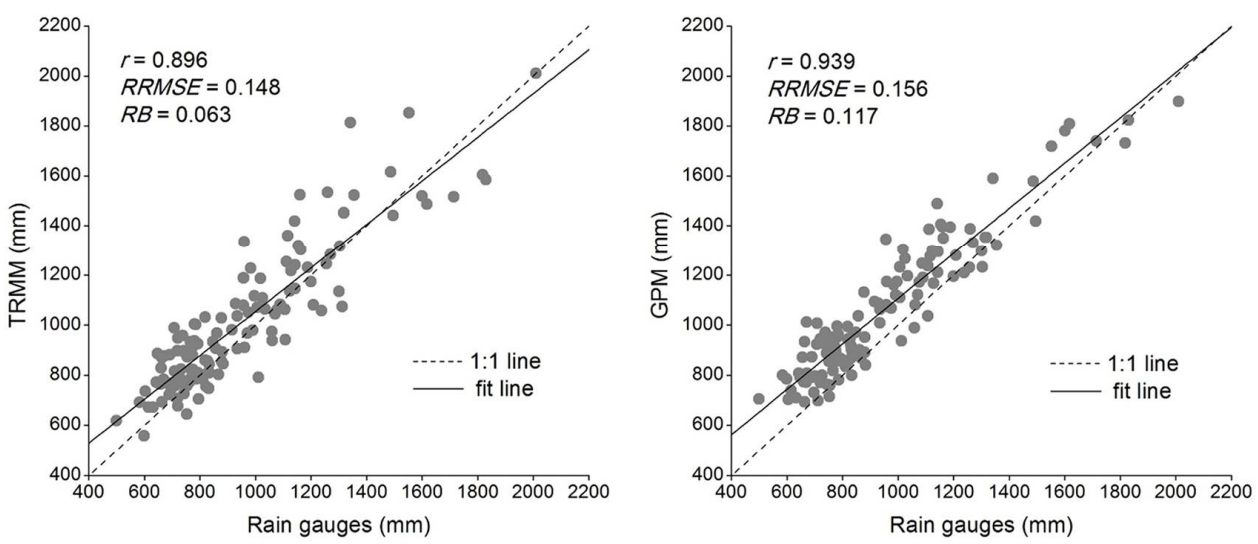

(c) Annual

Figure 2. Scatterplots for TRMM 3B42 v7 and GPM IMERG v5 precipitation versus gauge measurements from 2015 to 2017 over the Huaihe River basin: (a-c) daily, monthly, and annual scales, respectively.

Figures 3 and 4 show the time series of RRMSE for mean daily and monthly precipitation from 2015 to 2017 over the Huaihe River basin, respectively. The RRMSE was calculated by comparing the satellite precipitation products against the corresponding 43 rain gauges data at daily and monthly scales. The mean daily and monthly precipitation values were calculated by averaging all observations from the 43 stations in the study area. It is seen in Figure 3 that the mean daily precipitation was large during summer (June, July and August) and was small during winter (December, January, 
and February). The relatively large values of RRMSE occurred in October and December of 2016. Figure 4 demonstrates that the monthly precipitation was concentrated mainly from May to October, except the precipitation in November of 2015 and October of 2016 was abnormally large. Both satellite products agreed very well with the rain gauge data at monthly scale. The large RRMSE occurred mainly in winter, while the low RRMSE occurred in summer. Overall, the RRMSE of IMERG v5 was lower than that of 3B42 v7, especially in winter, which demonstrated the IMERG v5 data had better accuracy in the Huaihe River basin.

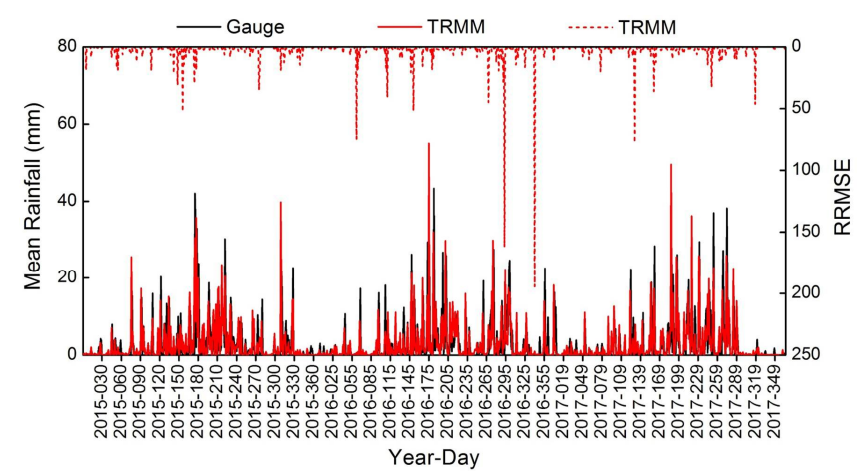

(a)

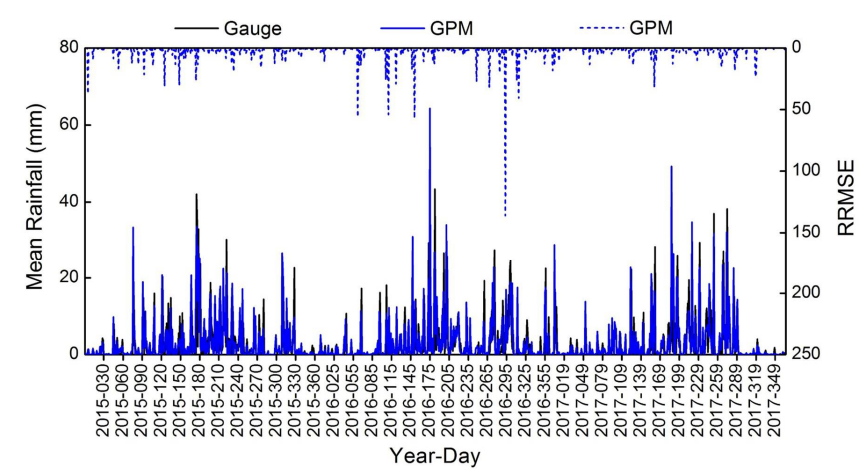

(b)

Figure 3. Time series of RRMSE (dash line) and mean daily precipitation (solid line) from 2015 to 2017 over the Huaihe River basin: (a) TRMM 3B42 v7, (b) GPM IMERG v5.

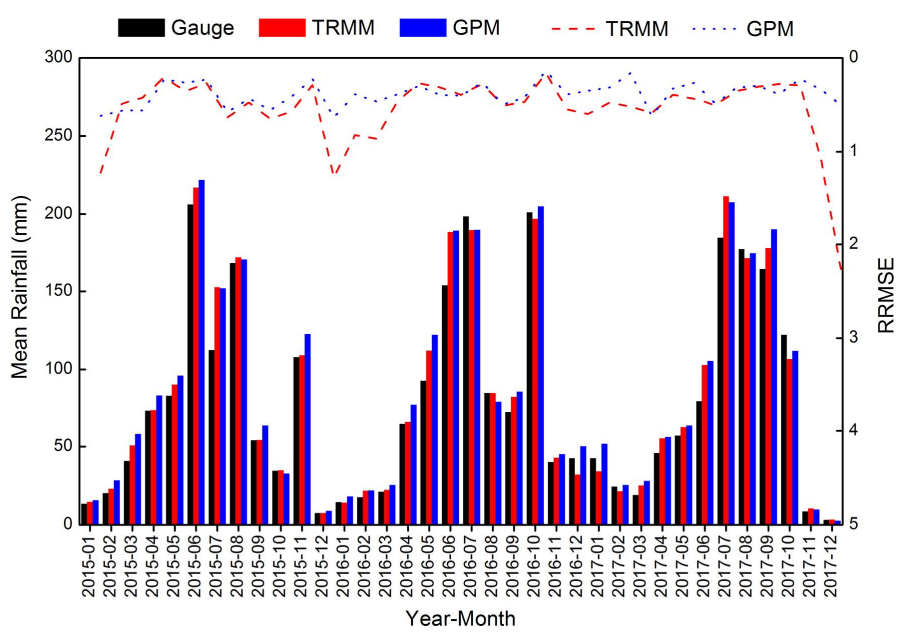

Figure 4. Time series of RRMSE (dot/dash line) and mean monthly precipitation (bar graph) from 2015 to 2017 over the Huaihe River basin. 
Figure 5 shows the spatial distribution of mean daily precipitation from 2015 to 2017 retrieved from TRMM 3B42 v7 and GPM IMERG v5 in the Huaihe River basin. The spatial patterns of two satellite precipitation products were similar, with precipitation decreasing from the southeast to the northwest. It was found that rainfall greater than $4.0 \mathrm{~mm} /$ day mainly occurred in the south and southeast of the Huaihe River basin, while the relatively small rainfall occurred in the west and north. A distinct dividing line appears with the mean daily precipitation value of about $2.2 \mathrm{~mm} /$ day (approximately $800 \mathrm{~mm} /$ year), which could be explained as the geographical boundary between China's southern and northern regions. Additionally, the abnormal blue pixels in Nansi lake, Luoma lake, Hongze lake, and Nanwan reservoir in Figure 5 show that the TRMM 3B42 v7 precipitation exhibited significant overestimation over water bodies, while the GPM IMERG v5 precipitation provided more consistent precipitation estimates with much lower systematic overestimation in these areas due to the employment of a unified and updated PMW retrieval algorithm (GPROF V05).

(a) TRMM 3B42 v7

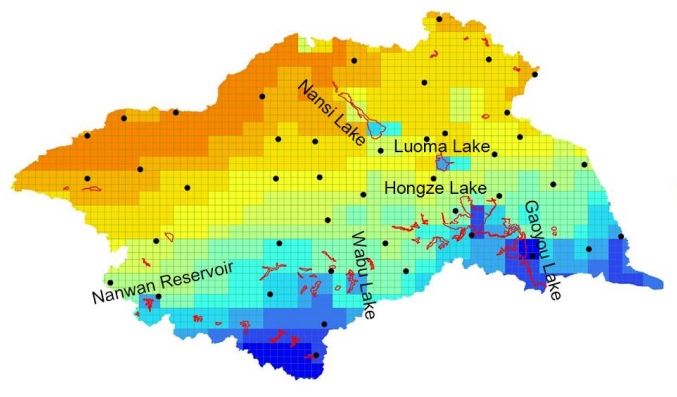

Rainfall (mm/d) (b) GPM IMERG v5

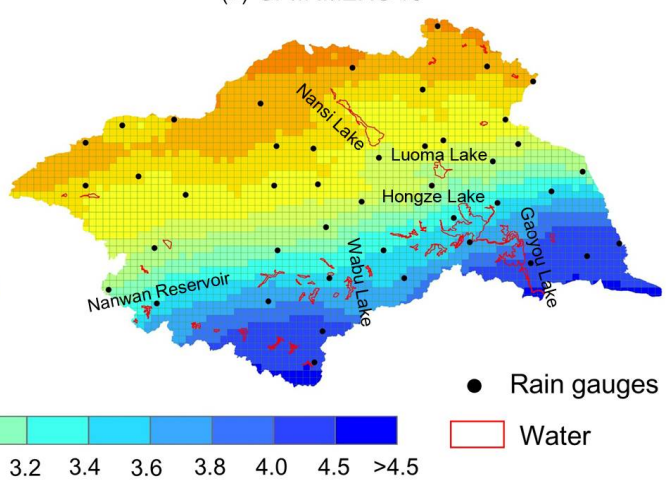

Figure 5. Spatial distribution of TRMM 3B42 v7 (a) and GPM IMERG v5 (b) mean daily precipitation from 2015 to 2017 in the Huaihe River basin.

\subsection{Evaluation and Comparison at Each Individual Gauge Station}

Figure 6 shows the point-based evaluation results of TRMM 3B42 v7 and GPM IMERG v5 daily gridded-precipitation retrievals against each rain gauge over the Huaihe River basin from 2015 to 2017. The $r$ varied widely at each individual station and was $0.06-0.58$ for $3 \mathrm{~B} 42 \mathrm{v} 7$ and $0.14-0.64$ for IMERG v5, respectively. The mean values of $r$ for IMERG v5 were slightly better than that of 3B42 v7, which indicated that the GPM precipitation data had a higher consistency with gauge station records. The mean values of RRMSE were 1.88 for 3B42 v7 and 1.73 for IMERG v5. Both satellite precipitation products had negative $R B$, demonstrating that the underestimation of satellite precipitation occurred at all gauge stations.

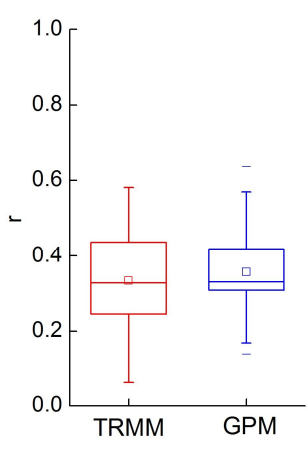

(a)

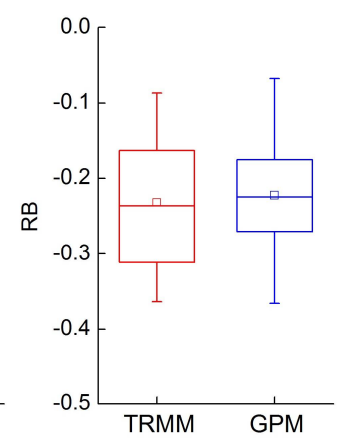

(b)

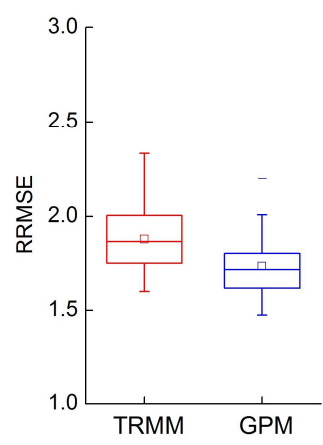

(c)

Figure 6. Evaluation results of TRMM 3B42 v7 and GPM IMERG v5 daily precipitation at individual gauge stations: $(\mathbf{a}-\mathbf{c})$ represent $r, R B$ and $R R M S E$, respectively. 
Figure 7 shows the spatial distribution of the evaluation results at each gauge station over the Huaihe River basin during the timeframe 2015-2017. Figure 7a shows the statistical results of mean annual rainfall at each gauge station, and Figure $7 \mathrm{~b}, \mathrm{~d}$ represents the $r, R B$, and RRMSE of 3B42 v7 and IMERG v5 precipitation estimates, respectively. The lower $r$ values were mainly distributed in the western and northern parts of the study area, where the terrain is relatively complex. The large absolute $R B$ generally occurred at the gauge station with small mean annual precipitation. It could be because the rainy days at this gauge station were few, while the satellite precipitation was generally not zero. It was found that $r$ of IMERG v5 was larger than the one of 3B42 v7 in the northwest of the Huaihe River basin while lower in the southeast; however, the absolute $R B$ showed the contrary pattern. The RRMSE of 3B42 v7 was larger than that of IMERG v5 in all 43 stations.

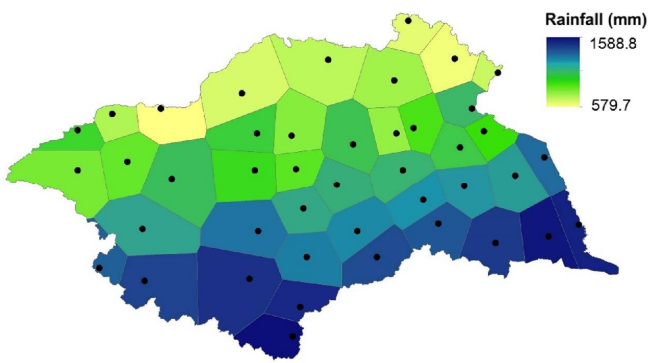

(a)

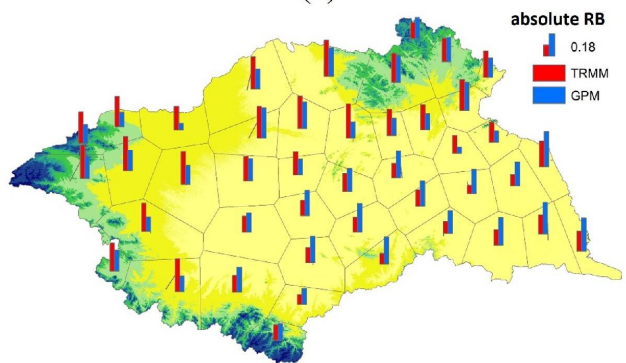

(c)

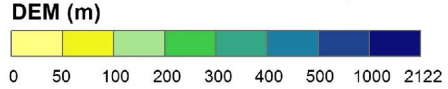

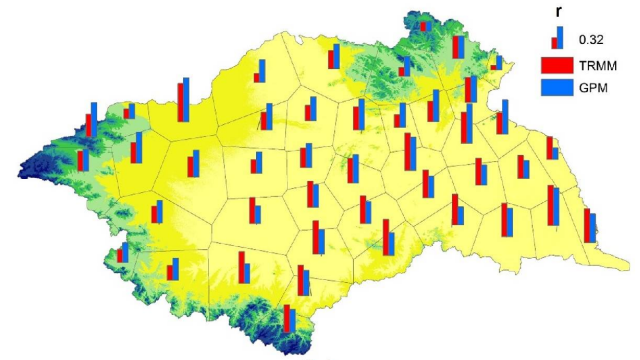

(b)

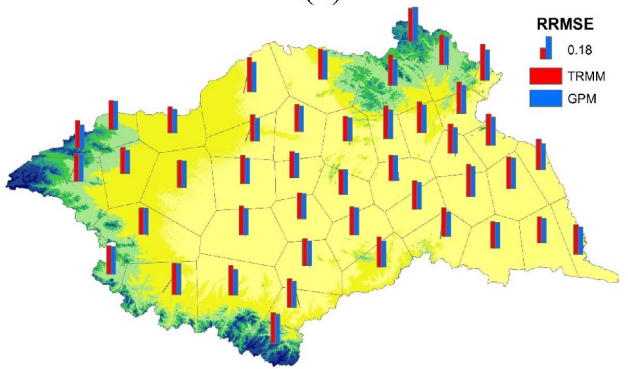

(d)

$\bigwedge^{N} \stackrel{0}{\square} 50100 \mathrm{~km} \quad \square$ Thiessen polygon

Figure 7. Evaluation results at each individual gauge station in the Huaihe River basin from 2015 to 2017. (a) Annual rainfall of rain gauge; (b-d) $r$, absolute RB, and RRMSE of 3B42 v7 and IMERG v5 precipitation products.

To further analyze the influence of elevation and mean annual precipitation on the $r$, absolute $R B$ and $R R M S E$ at each gauge station, a regression analysis was conducted, and the optimal fitting results are shown in Table 3. The elevation had a negative correlation with $r$ (logarithmic regression). The RRMSE of IMERG v5 had a linear correlation with elevation $(r=0.38)$, and the $r$ of $3 \mathrm{~B} 42 \mathrm{v} 7 \mathrm{had}$ a linear correlation with mean annual rainfall.

Table 3. Regression results of three statistical metrics versus elevation and annual rainfall at all gauge stations.

\begin{tabular}{cccccccc}
\hline & \multicolumn{9}{c}{$r$} \\
\cline { 2 - 7 } & \multicolumn{3}{c}{$r$} & \multicolumn{2}{c}{ Absolute RB } & \multicolumn{2}{c}{ RRMSE } \\
\cline { 2 - 7 } & TRMM & GPM & TRMM & GPM & TRMM & GPM \\
\hline Elevation & $-0.40^{\log }$ & $-0.42^{\log }$ & $\#$ & $\#$ & $\#$ & $0.38^{\operatorname{lin}}$ \\
Annual rainfall & $0.56^{\operatorname{lin}}$ & $\#$ & $-0.54^{\exp }$ & $0.36^{\exp }$ & $\#$ & $\#$ \\
\hline
\end{tabular}

Notation: The symbol "\#" means the regression results were not significant; Superscript represents the optimal fit, where "exp" means exponential regression, "lin" means linear regression, and "log" means logarithmic regression. 


\subsection{Performance of Satellite Precipitation Estimates at Different Rainfall Thresholds}

Figure $8 \mathrm{a}, \mathrm{b}$ presents the probability distribution function (PDF) and the mean daily precipitation estimated by gauge data and satellite products at different rainfall thresholds. The PDF and mean daily precipitation are of great importance for hydrological applications. The PDF of the two satellite precipitation products in Figure 8a were mainly concentrated at the rainfall rate of $0-0.5 \mathrm{~mm} /$ day (above 35\%). The 3B42 v7 and IMERG v5 precipitation estimates had an obvious overestimation of PDF at small rainfall from $0-0.5 \mathrm{~mm} /$ day, while there was a tendency to underestimate the gauge precipitation when the rainfall rate was greater than $0.5 \mathrm{~mm} /$ day. The satellite precipitation estimates show similar mean daily precipitation to gauge observations in Figure $8 \mathrm{~b}$. The satellite estimates overestimated the mean daily precipitation at the rainfall rates from 0.5 to $25 \mathrm{~mm} /$ day, but tended to underestimate light $(0-0.5 \mathrm{~mm} /$ day) and heavy $(>25 \mathrm{~mm} /$ day) precipitation. Specifically, there was an obvious underestimation when the rainfall rates were greater than $100 \mathrm{~mm} /$ day.

The daily results of three metrics ( $P O D, C S I$, and FAR) for different rainfall thresholds are shown in Figure 9. High values of $P O D$ and $C S I$ at rainfall rates from $0.5-2.0 \mathrm{~mm} /$ day indicated that satellite precipitation estimates had better performance. The POD and CSI were reduced, and the FAR was increased with increasing rainfall rate, which indicated the limited capability of satellite sensors for detecting heavy rainfall events. The relatively high POD and CSI also showed that IMERG v5 was better than 3B42 $\mathrm{v} 7$ for detecting precipitation in the study area, especially for rainfall rates of 0-2.0 mm/day.

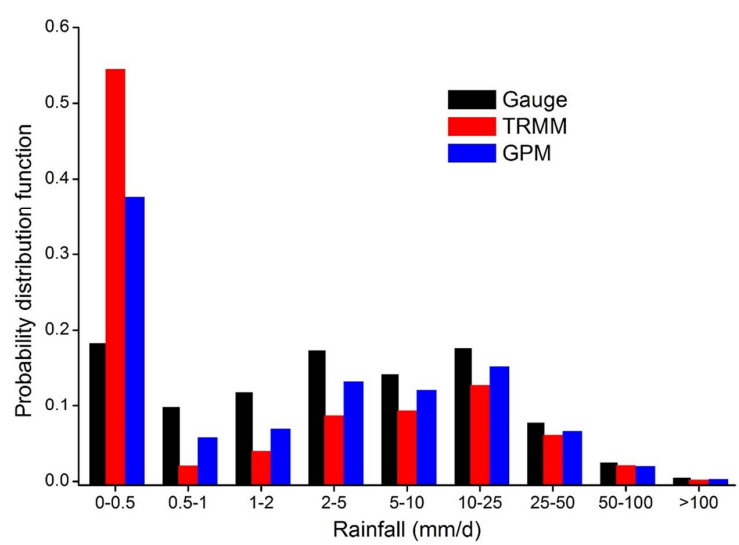

(a)

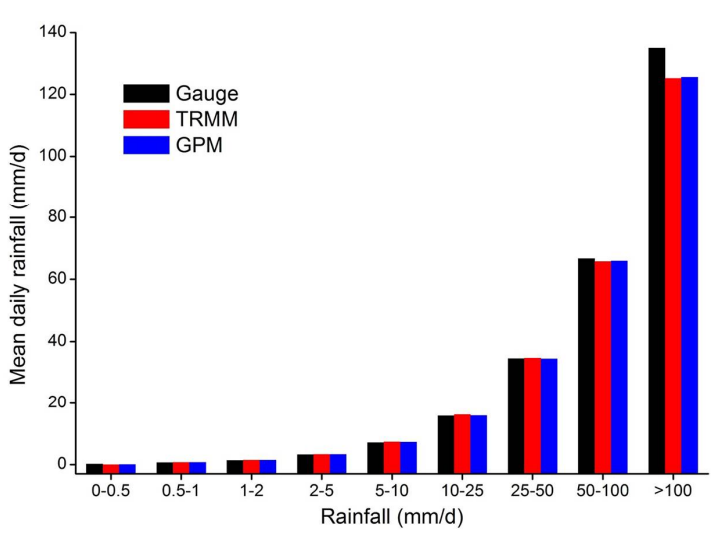

(b)

Figure 8. Probability distribution function (a) and mean daily precipitation (b) at different rainfall thresholds.

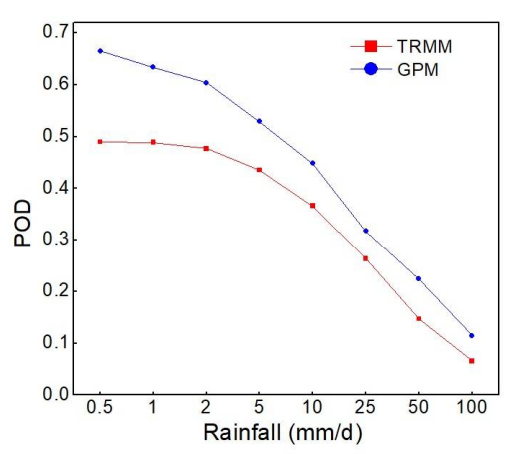

(a)

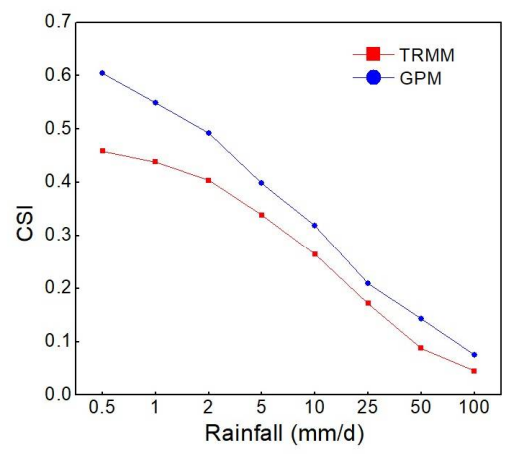

(b)

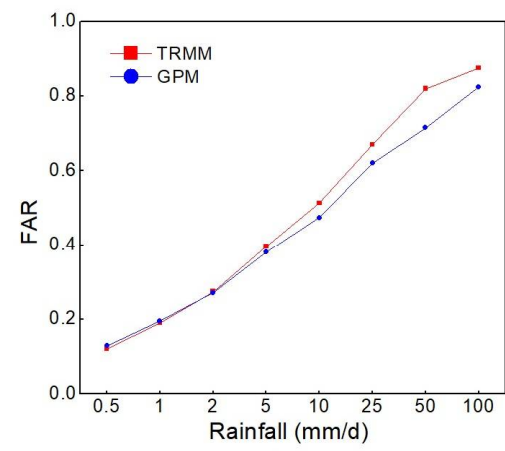

(c)

Figure 9. Daily results of three metrics for different rainfall thresholds: (a-c) represent POD, CSI, and $F A R$, respectively. 


\subsection{Influence of Latitude and Elevation on Satellite Precipitation}

Figure 10 shows the continuous rainfall events of the rain gauge, 3B42 v7 and IMERG v5 precipitation data over the Huaihe River basin from 2015 to 2017. The daily rainfall rate was plotted according to its occurrence time and latitude. Both satellite products could better characterize the gauge precipitation distribution, while the relatively sparse gauge sites led to the loss of some important rainfall events, such as the rainfall events from $31^{\circ}-34^{\circ} \mathrm{N}$ in late January and the strong precipitation in November. Satellite precipitation estimates can effectively detect spatial precipitation patterns and might be an alternative in the areas where the rain gauge stations are sparse.

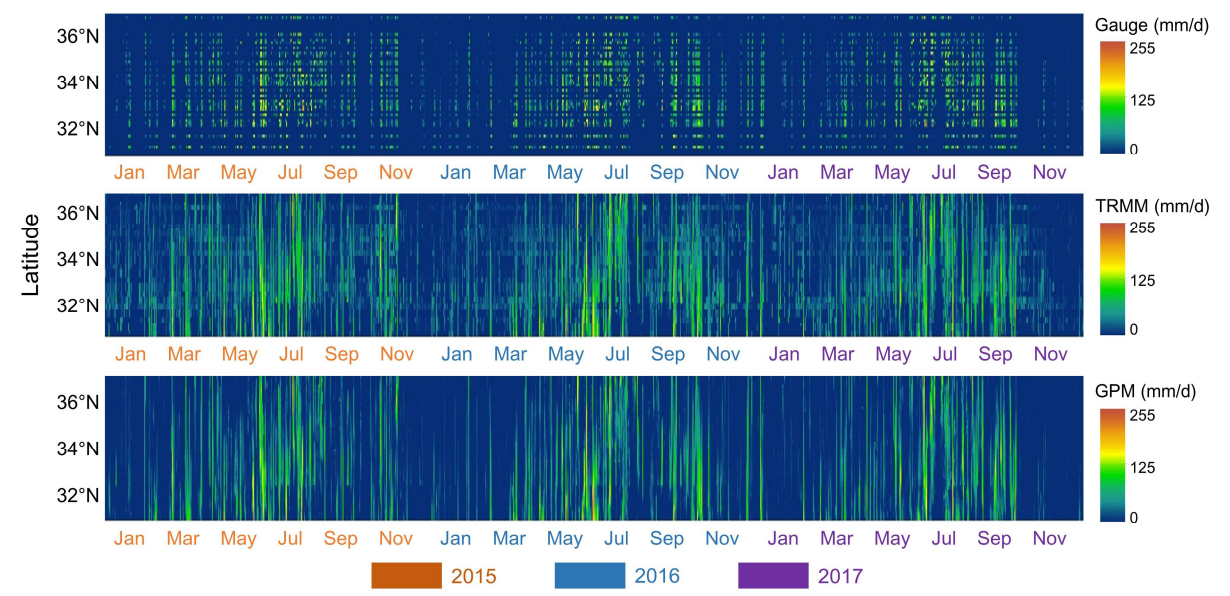

Figure 10. Comparison of satellite products (TRMM 3B42 v7 and GPM IMERG v5) and gauge observations with latitudes over the Huaihe River basin from 2015 to 2017.

Figure 11 presents the scatterplots of mean daily satellite precipitation against elevation over the Huaihe River basin. The points in Figure 11 with different colors representing the rainfall at different thresholds. The gray and black dots represent the mean daily satellite precipitation below and above the threshold rainfall rate of $3.0 \mathrm{~mm} /$ day, respectively. Various regression methods such as logarithm regression, exponential regression, and linear regression were tried to choose the best fitted regression between elevation and precipitation. The relationship between topography and precipitation was not significant over the whole basin. However, for rainfall rates less than $3.0 \mathrm{~mm} /$ day, the precipitation decreased logarithmically with elevation (the $r$ values were 0.43 for 3B42 v7 and 0.45 for IMERG v5); for rainfall rates greater than $3.0 \mathrm{~mm} /$ day, the precipitation increased linearly with elevation (the $r$ values were 0.55 for 3B42 v7 and 0.34 for IMERG v5).

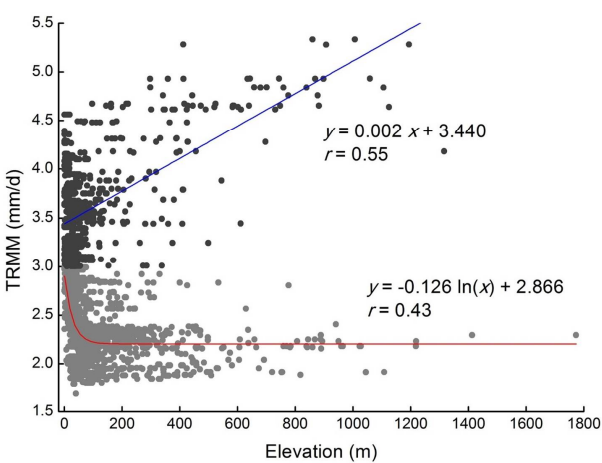

(a)

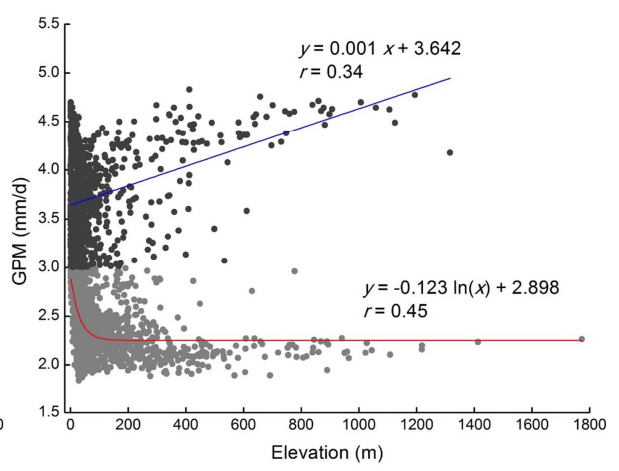

(b)

Figure 11. Scatterplots of mean daily precipitation of TRMM 3B42 v7 (a) and GPM IMERG v5 (b) precipitation products against the elevation over the Huaihe River basin. 


\section{Discussion}

It should be highlighted that this study was the first to assess the performance of the latest released IMERG v5 precipitation product for three complete years of 2015-2017 over the climatic transition zone of the Huaihe River basin. It was found that both satellite precipitation products significantly underestimated the gauge precipitation ( $R B$ was -0.273 for 3B42 v7 and -0.176 for IMERG v5) and had relatively small $r$ when the gauge stations with zero rainfall were eliminated in Figure $2 \mathrm{a}$, which was mainly due to the absence of the whole rainfall process record of the satellite sensors (the temporal resolutions for IMERG v5 and 3B42 v7 are half-hourly and 3-hourly) leading to the inaccurate monitor of the smaller rainfall events. Usually, the TRMM precipitation radar (PR), whose emission wavelengths are relatively long, has a minimum measurable rain rate as low as $0.7 \mathrm{~mm} / \mathrm{h}$ [39]. While a key advancement of GPM is the extended capability to measure light rain (less than $0.5 \mathrm{~mm} / \mathrm{h}$ ), solid precipitation, and the microphysical properties of precipitating particles compared to TRMM; the GPM Dual-frequency Precipitation Radar (DPR) is more sensitive to light rain rates and snowfall [10]. Additionally, simultaneous measurement by the overlapping of $\mathrm{Ka} / \mathrm{Ku}$-bands of the DPR provides new information on particle drop size distributions over moderate precipitation intensities. Thus, the absolute $R B$ of IMERG v5 shown in Figure 2a was relatively lower than that of 3B42 v7 at daily scale.

The GPM IMERG v5 and TRMM 3B42 v7 precipitation products overestimated precipitation at monthly and annual scales (Figure $2 b, c$ ), which was mainly because the satellite precipitation estimates were usually greater than zero when the gauges showed no rainfall. When the time scale increased, the $r$ values were significantly improved, and the RRMSE values were significantly reduced. Similar findings have been reported in previous evaluation results [15,22]. A reason for the higher accuracy of satellite precipitation products at monthly and annual scales was that the GPCC monthly product was used for bias-correction of the 3B42 v7 and IMERG v5 products [11,40].

A solid understanding of the distribution of daily precipitation is of great importance in hydrological applications. PDF emphasizes lighter rainfall rates, making it more suitable for evaluating the ability of satellite precipitation to detect light precipitation [14]. The PDF of satellite precipitation shown in Figure 8a was consistent with that of gauge observations for the rainfall rate greater than $0.5 \mathrm{~mm} / \mathrm{day}$ and tended to underestimate the gauge precipitation in this study. An obvious overestimation of satellite precipitation frequency occurred during light rainfall from 0-0.5 mm/day. Yang and Geng [23] also reported that the TRMM-era precipitation estimates tended to underestimate light rainfall. The precipitation distribution in Figure $8 \mathrm{~b}$ showed an underestimation of satellite estimates when the rainfall rates were either less than $0.5 \mathrm{~mm}$ /day or greater than $25 \mathrm{~mm} /$ day. Ebrahimi et al. [41] pointed out that satellite sensors are not sensitive to light rainfall and heavy rainfall, which might lead to unsatisfactory monitoring of extreme rainfall. The IMERG v5 product, with relatively high POD and CSI, showed better performance in precipitation detection of the Huaihe River basin. This was mainly because the GPM combined Instrument (GMI) sensor can capture light precipitation better than the TRMM combined Instrument (TMI) [42]. Additionally, Figure 9 demonstrated the FAR was increased, but the POD and CSI were reduced with increasing rainfall rate for the two satellite precipitation products, suggesting the limited capability of satellite sensors in detecting intense rainfall events [24]. Conversely, the high intensity rainfall makes radar signals attenuate, so the strong rainfall cannot be accurately measured [43]. Then again, because the satellite precipitation is the homogenization data of the grid downscaling, it is unable to reflect the local heavy rainfall characteristics.

It is widely acknowledged that topography has a strong effect on precipitation [44-46], and the relationship between altitude and precipitation varies in different regions, especially in the climatic transition region. During this study, the negative logarithmic relationship between elevation and mean daily rainfall was found when the rainfall rate was less than $3.0 \mathrm{~mm} /$ day, which could be due to the effect of terrain and latitude [47]. The rainfall increased linearly with topography when the rainfall rates were above $3.0 \mathrm{~mm} /$ day. Regions where the precipitation rates were above $3.0 \mathrm{~mm} /$ day were generally located in the south of the Huaihe River basin (also to the south of $35^{\circ} \mathrm{N}$, see Figures 1 and 5 ). This could be attributed to the effects of the western Pacific subtropical high (abbreviated as subtropical high), 
which is one of the main atmospheric circulation systems influencing the weather and climate change in China [48]. The southward-northward shift of the precipitation belt in China is consistent with the seasonal activities of the subtropical high, and rainfall is usually located at $5^{\circ}-8^{\circ}$ latitude north of the ridge position of the subtropical high [49,50]. During summer, the ridge of the subtropical high is located at about $25^{\circ} \mathrm{N}$. The southern part of the Huaihe River basin is under the subtropical high influence, and such influence decreases with latitude. Since the elevation in the south of the Huaihe River basin also decreases with latitude, precipitation increases with elevation when the precipitation rates were above $3.0 \mathrm{~mm} /$ day. The different regression relationships between elevation and precipitation were found and the results were discussed from the perspective of atmospheric circulation, which could provide the reference for the study of rainfall in other climatic transition regions.

IMERG v5 had larger $r$ and smaller RRMSE than 3B42 v7 on multiple temporal scales. The relatively high POD and CSI of IMERG v5 also indicated its higher detection ability for daily rainfall, especially for rainfall rates of 0-2.0 mm/day. Daily precipitation or even hourly precipitation is very important input for hydrological models. The lack of dense rain gauges at the basin scale leads to great uncertainty in practical hydrological simulations [51]. IMERG v5, which has high temporal resolution and accuracy, might have better potential in future hydrological applications. The GPM precipitation with higher spatial resolution $\left(0.1^{\circ}\right)$ showed a better ability for precipitation observation in small areas compared to the coarse resolution $\left(0.25^{\circ}\right)$ of the TRMM products on a spatial scale. Additionally, IMERG v5 can make up for the limitations of 3B42 v7 regarding detecting rainfall over water bodies due to the employment of a unified and updated PMW retrieval algorithm [52]. It was demonstrated that IMERG v5 was more suitable for characterizing the spatial variation of precipitation. However, it is worth pointing out that the accuracy of satellite precipitation at daily scale is still poor, which limits the application of satellite precipitation products to some extent [41]. Xu et al. [40] found that the performance of GPM and TRMM strongly depends on topography and rainfall intensity over the southern Tibetan Plateau. Since the accuracy of satellite precipitation products usually is affected by the rainfall rate, latitude, and elevation in the climate transition zone, fusion of multi-source precipitation products (satellite, radar and measured data) and geographic background information (terrain and geographic location) to enhance the spatiotemporal accuracy of IMERG v5 data will be the hot spot of future study.

It should be noted that the 3B42 v7 data in this study were resampled to the same spatial resolution $\left(0.1^{\circ}\right)$ as IMERG $v 5$ data by using the standard bilinear interpolation method to make them comparable $[13,15]$. However, potential errors would possibly be introduced during the resampling procedure. To investigate the impact of the interpolation method, the error analysis of the initial TRMM $3 \mathrm{~B} 42 \mathrm{v} 7$ data $\left(0.25^{\circ}\right)$ was conducted and the evaluation results were shown in Table 2 . It was found that the GPM IMERG v5 $\left(0.1^{\circ}\right)$ as a whole had the best performance. The initial $\left(0.25^{\circ}\right)$ and the interpolated $\left(0.1^{\circ}\right)$ TRMM data had different performances at multiple scales, which demonstrated that the comparison of different interpolation methods is necessary to obtain higher precision for precipitation. Moreover, the nearest pixel to a rain gauge was extracted to conduct the comparison between the point-based rain gauge and pixel-based GPM or TRMM in the study. However, there is a typical scale mismatch issue between point-based rain gauge data and the gridded precipitation products [22]. Many interpolation methods (inverse distance weighting, kriging, spline, and Thiessen polygon for example) $[22,33,53]$ and grid-to-point techniques (such as nearest neighbor, bilinear weighted interpolation) [41] have been proposed to compare the point-based rain gauge data and pixel-based satellite precipitation data. Each method has its advantages and disadvantages, and its performance depends on various factors and varies from region to region [22]. It is an interesting topic to develop a common method in all study areas for comparing the point-based rain gauge and pixel-based satellite precipitation.

\section{Conclusions}

An early and comprehensive assessment of the latest released GPM IMERG v5 and TRMM 3B42 v7 precipitation products was carried out over the Huaihe River basin with a climate transition. The accuracy of satellite precipitation retrievals was typically influenced by the rainfall rate and 
local topographical features in the climate transition zone. Both satellite precipitation products agreed with the gauge observations at monthly and annual scales, providing effective data source for hydrometeorology research to supplement sparse gauge observations. However, significant overestimation of daily precipitation at each individual gauge station was found, indicating the necessity for evaluation before application with certainty. The initial assessment on detecting rainfall event frequency at different rainfall thresholds showed that both products overestimated precipitation distribution at the rainfall rates 0.5 to $25 \mathrm{~mm} /$ day, but tended to underestimate light $(0-0.5 \mathrm{~mm} /$ day $)$ and heavy ( $>25 \mathrm{~mm} /$ day) precipitation (especially for the torrential rain, above $100 \mathrm{~mm} /$ day) in the basin. The latest released IMERG v5 product had better performance for detecting precipitation and provided more accurate precipitation estimates than TRMM 3B42 v7 data due to finer spatial and temporal resolutions. Therefore, there is an urgent need to assess the potential of the GPM IMERG v5 product in hydrological application in a range of different environments.

Author Contributions: C.C. analyzed the data and wrote the draft of the manuscript; C.C. and Z.D. performed the experiments; Z.L., J.Z. and G.T. gave comments and revised the manuscript; K.M. handled the gauge data. Q.C. conceived of this study, gave comments and significantly revised the manuscript.

Funding: This research was supported by the National Key Research and Development Program of China (2016YFC0502205, 2016YFC0400902), the National Natural Science Foundation of China (51709179) and the fund of Nanjing Hydraulic Research Institute (Y918011).

Acknowledgments: We are grateful to the providers of operational satellite precipitation products and rain gauge measurements for making data available to us.

Conflicts of Interest: The authors declare no conflict of interest.

\section{References}

1. Langella, G.; Basile, A.; Bonfante, A.; Terribile, F. High-resolution space-time rainfall analysis using integrated ann inference systems. J. Hydrol. 2010, 387, 328-342. [CrossRef]

2. Duan, Z.; Bastiaanssen, W.G.M. First results from Version 7 TRMM 3B43 precipitation product in combination with a new downscaling-calibration procedure. Remote Sens. Environ. 2013, 131, 1-13. [CrossRef]

3. Chen, C.; Zhao, S.; Duan, Z.; Qin, Z. An improved spatial downscaling procedure for TRMM 3B43 precipitation product using geographically weighted regression. IEEE J. Sel. Top. Appl. Earth Obs. Remote Sens. 2015, 8, 4592-4604. [CrossRef]

4. Allen, M.R.; Ingram, W.J.; Stainforth, D.A. Constraints on future changes in climate and the hydrologic cycle. Nature 2002, 419, 224. [CrossRef] [PubMed]

5. Sorooshian, S.; Hsu, K.L.; Gao, X.; Gupta, H.V.; Imam, B.; Dan, B. Evaluation of persiann system satellite-based estimates of tropical rainfall. Bull. Am. Meteorol. Soc. 2000, 81, 2035-2046. [CrossRef]

6. Joyce, R.J.; Janowiak, J.E.; Arkin, P.A.; Xie, P. CMORPH: A method that produces global precipitation estimates from passive microwave and infrared data at high spatial and temporal resolution. J. Hydrometeorol. 2004, 5, 487-503. [CrossRef]

7. Kubota, T.; Shige, S.; Hashizume, H.; Aonashi, K.; Takahashi, N.; Seto, S.; Kachi, M. Global precipitation map using satellite-borne microwave radiometers by the GSMaP project: Production and validation. IEEE Trans. Geosci. Remote Sens. 2007, 45, 2259-2275. [CrossRef]

8. Funk, C.; Peterson, P.; Landsfeld, M.; Pedreros, D.; Verdin, J.; Shukla, S.; Michaelsen, J. The climate hazards infrared precipitation with stations-A new environmental record for monitoring extremes. Sci. Data 2015, 2, 150066. [CrossRef] [PubMed]

9. Huffman, G.J.; Bolvin, D.T.; Nelkin, E.J.; Wolff, D.B.; Adler, R.F.; Gu, G.; Stocker, E.F. The TRMM multisatellite precipitation analysis (TMPA): Quasi-global, multiyear, combined-sensor precipitation estimates at fine scales. J. Hydrometeorol. 2007, 8, 38-55. [CrossRef]

10. Hou, A.Y.; Kakar, R.K.; Neeck, S.; Azarbarzin, A.A.; Kummerow, C.D.; Kojima, M.; Iguchi, T. The global precipitation measurement mission. Bull. Am. Meteorol. Soc. 2014, 95, 701-722. [CrossRef]

11. Huffman, G.J.; Bolvin, D.T.; Braithwaite, D.; Hsu, K.; Joyce, R.; Xie, P.; Yoo, S.H. NASA global precipitation measurement (GPM) integrated multi-satellite retrievals for GPM (IMERG). In Algorithm Theoretical Basis Document (ATBD); NASA/GSFC: Greenbelt, MD, USA, 2014. 
12. Huffman, G.J.; Bolvin, D.T.; Nelkin, E.J. Integrated Multi-SatellitE Retrievals for GPM (IMERG) Technical Documentation; NASA/GSFC Code; NASA/GSFC: Greenbelt, MD, USA, 2015.

13. Tang, G.; Ma, Y.; Long, D.; Zhong, L.; Hong, Y. Evaluation of GPM Day-1 IMERG and TMPA Version-7 legacy products over Mainland China at multiple spatiotemporal scales. J. Hydrol. 2016, 533, 152-167. [CrossRef]

14. Tang, G.; Zeng, Z.; Long, D.; Guo, X.; Yong, B.; Zhang, W.; Hong, Y. Statistical and hydrological comparisons between TRMM and GPM level-3 products over a midlatitude basin: Is day-1 IMERG a good successor for TMPA 3B42V7? J. Hydrometeorol. 2016, 17, 121-137. [CrossRef]

15. Ma, Y.; Tang, G.; Long, D.; Yong, B.; Zhong, L.; Wan, W.; Hong, Y. Similarity and error intercomparison of the GPM and its predecessor-TRMM Multisatellite Precipitation Analysis using the best available hourly gauge network over the Tibetan Plateau. Remote Sens. 2016, 8, 569. [CrossRef]

16. Gaona, M.R.; Overeem, A.; Leijnse, H.; Uijlenhoet, R. First-Year Evaluation of GPM Rainfall over The Netherlands: IMERG Day 1 Final Run (V03D). J. Hydrometeorol. 2016, 17, 2799-2814. [CrossRef]

17. Prakash, S.; Mitra, A.K.; AghaKouchak, A.; Liu, Z.; Norouzi, H.; Pai, D.S. A preliminary assessment of GPM-based multi-satellite precipitation estimates over a monsoon dominated region. J. Hydrol. 2016, 556, 865-875. [CrossRef]

18. Prakash, S.; Mitra, A.K.; Pai, D.S.; AghaKouchak, A. From TRMM to GPM: How well can heavy rainfall be detected from space? Adv. Water Resour. 2016, 88, 1-7. [CrossRef]

19. Asong, Z.E.; Razavi, S.; Wheater, H.S.; Wong, J.S. Evaluation of Integrated Multisatellite Retrievals for GPM (IMERG) over Southern Canada against Ground Precipitation Observations: A Preliminary Assessment. J. Hydrometeorol. 2017, 18, 1033-1050. [CrossRef]

20. Tan, M.L.; Duan, Z. Assessment of GPM and TRMM Precipitation Products over Singapore. Remote Sens. 2017, 9, 720. [CrossRef]

21. Li, Z.; Yang, D.; Gao, B.; Jiao, Y.; Hong, Y.; Xu, T. Multiscale hydrologic applications of the latest satellite precipitation products in the Yangtze River Basin using a distributed hydrologic model. J. Hydrometeorol. 2015, 16, 407-426. [CrossRef]

22. Duan, Z.; Liu, J.; Tuo, Y.; Chiogna, G.; Disse, M. Evaluation of eight high spatial resolution gridded precipitation products in Adige Basin (Italy) at multiple temporal and spatial scales. Sci. Total Environ. 2016, 573, 1536-1553. [CrossRef] [PubMed]

23. Yang, X.; Geng, W. Accuracy evaluation of TRMM-based Multi-satellite Precipitation in Huai River Basin. Water Resour. Power. 2016, 34, 1-5.

24. Sun, R.; Yuan, H.; Liu, X.; Jiang, X. Evaluation of the latest satellite-gauge precipitation products and their hydrologic applications over the Huaihe River basin. J. Hydrol. 2016, 536, 302-319. [CrossRef]

25. Stocker, E.F.; Kelley, O. GPM V05 Gridded Text Products. Available online: https://ntrs.nasa.gov/search. jsp?R=20170009623 (accessed on 2 December 2017).

26. Zulkafli, Z.; Buytaert, W.; Onof, C.; Manz, B.; Tarnavsky, E.; Lavado, W.; Guyot, J.L. A comparative performance analysis of TRMM 3B42 (TMPA) versions 6 and 7 for hydrological applications over Andean-Amazon river basins. J. Hydrometeorol. 2014, 15, 581-592. [CrossRef]

27. Huffman, G.J.; Bolvin, D.T. TRMM and Other Data Precipitation Data Set Documentation, Mesoscale Atmospheric Processes Laboratory, NASA Global Change Master Directory Doc. Available online: https: // pmm.nasa.gov/sites/default/files/document_files/3B42_3B43_doc_V7.pdf (accessed on 8 April 2015).

28. Sandwell, D.T. Biharmonic spline interpolation of GEOS-3 and SEASAT altimeter data. Geophys. Res. Lett. 1987, 14, 139-142. [CrossRef]

29. Tan, M.L.; Santo, H. Comparison of GPM IMERG, TMPA 3B42 and PERSIANN-CDR satellite precipitation products over Malaysia. Atmos. Res. 2018, 202, 63-76. [CrossRef]

30. Duan, L.; Fan, K.; Li, W.; Liu, T. Spatial downscaling algorithm of TRMM precipitation based on multiple high-resolution satellite data for Inner Mongolia, China. Theor. Appl. Climatol. 2017, 1-15. [CrossRef]

31. Zhang, Q.; Singh, V.P.; Li, J.; Chen, X. Analysis of the periods of maximum consecutive wet days in China. J. Geophys. Res. Atmos. 2011, 116. [CrossRef]

32. Xu, W.; Li, Q.; Wang, X.L.; Yang, S.; Cao, L.; Feng, Y. Homogenization of Chinese daily surface air temperatures and analysis of trends in the extreme temperature indices. J. Geophys. Res. Atmos. 2013, 118, 9708-9720. [CrossRef] 
33. Yong, B.; Ren, L.L.; Hong, Y.; Wang, J.H.; Gourley, J.J.; Jiang, S.H.; Wang, W. Hydrologic evaluation of Multisatellite Precipitation Analysis standard precipitation products in basins beyond its inclined latitude band: A case study in Laohahe basin, China. Water Resour. Res. 2010, 46. [CrossRef]

34. Li, Z.; Yang, D.; Hong, Y. Multi-scale evaluation of high-resolution multi-sensor blended global precipitation products over the Yangtze River. J. Hydrol. 2013, 500, 157-169. [CrossRef]

35. Wang, W.; Lu, H.; Zhao, T.; Jiang, L.; Shi, J. Evaluation and comparison of daily rainfall from latest GPM and TRMM products over the Mekong River Basin. IEEE J. Sel. Top. Appl. Earth Obs. Remote Sens. 2017, 10, 2540-2549. [CrossRef]

36. Wilks, D.S. Statistical Methods in the Atmospheric Sciences; Academic Press: Cambridge, MA, USA, 2011.

37. Ebert, E.E.; Janowiak, J.E.; Kidd, C. Comparison of near-real-time precipitation estimates from satellite observations and numerical models. Bull. Am. Meteorol. Soc. 2007, 88, 47-64. [CrossRef]

38. El Kenawy, A.M.; Lopez-Moreno, J.I.; McCabe, M.F.; Vicente-Serrano, S.M. Evaluation of the TMPA-3B42 precipitation product using a high-density rain gauge network over complex terrain in northeastern Iberia. Global Planet. Chang. 2015, 133, 188-200. [CrossRef]

39. Kawanishi, T.; Takamatsu, H.; Kozu, T.; Okamoto, K.; Kumagai, H. TRMM precipitation radar. Adv. Space Res. 2000, 25, 969-972. [CrossRef]

40. Xu, R.; Tian, F.; Yang, L.; Hu, H.; Lu, H.; Hou, A. Ground validation of GPM IMERG and TRMM 3B42V7 rainfall products over southern Tibetan Plateau based on a high-density rain gauge network. J. Geophys. Res. Atmos. 2017, 122, 910-924. [CrossRef]

41. Ebrahimi, S.; Chen, C.; Chen, Q.; Zhang, Y.; Ma, N.; Zaman, Q. Effects of temporal scales and space mismatches on the TRMM 3B42 v7 precipitation product in a remote mountainous area. Hydrol. Process. 2017, 31. [CrossRef]

42. Sharifi, E.; Steinacker, R.; Saghafian, B. Assessment of GPM-IMERG and other precipitation products against gauge data under different topographic and climatic conditions in Iran: Preliminary results. Remote Sens. 2016, 8, 135. [CrossRef]

43. Cheema, M.; Bastiaanssen, W. Local calibration of remotely sensed rainfall from the TRMM satellite for different periods and spatial scales in the Indus Basin. Int. J. Remote Sens. 2012, 33, 2603-2627. [CrossRef]

44. Bonacina, L.C.W.; Poulter, R.; Ashmore, S.; Manley, G.; Bonacina, L. Orographic rainfall and its place in the hydrology of the globe. Q. J. Roy. Meteor. Soc. 1945, 71, 41-55.

45. Hughes, M.; Hall, A.; Fovell, R.G. Blocking in areas of complex topography, and its influence on rainfall distribution. J. Atmos. Sci. 2009, 66, 508-518. [CrossRef]

46. Kumari, M.; Singh, C.K.; Bakimchandra, O.; Basistha, A. Geographically weighted regression based quantification of rainfall-topography relationship and rainfall gradient in Central Himalayas. Int. J. Climatol. 2017, 37, 1299-1309. [CrossRef]

47. Qing, Y.; Zhu-Guo, M.A.; Liang, C. A preliminary analysis of the relationship between precipitation variation trends and altitude in China. Atmos. Ocean. Sci. Lett. 2011, 4, 41-46. [CrossRef]

48. Qu, W.; Wang, J.; Gao, S.; Wu, T. Effect of the strengthened western Pacific subtropical high on summer visibility decrease over eastern China since 1973. J. Geophys. Res. Atmos. 2013, 118, 7142-7156. [CrossRef]

49. Ueda, H.; Ohba, M.; Xie, S.P. Important factors for the development of the Asian-Northwest Pacific summer monsoon. J. Clim. 2009, 22, 649-669. [CrossRef]

50. Xie, S.P.; Hu, K.; Hafner, J.; Tokinaga, H.; Du, Y.; Huang, G.; Sampe, T. Indian Ocean capacitor effect on Indo-Western Pacific climate during the summer following El Niño. J. Clim. 2009, 22, 730-747. [CrossRef]

51. Meng, J.; Li, L.; Hao, Z.; Wang, J.; Shao, Q. Suitability of TRMM satellite rainfall in driving a distributed hydrological model in the source region of Yellow River. J. Hydrol. 2014, 509, 320-332. [CrossRef]

52. Tang, G.; Long, D.; Hong, Y. Systematic anomalies over inland water bodies of High Mountain Asia in TRMM precipitation estimates: No longer a problem for the GPM era? IEEE Geosci. Remote Sens. Lett. 2016, 13, 1762-1766. [CrossRef]

53. Awange, J.; Forootan, E. An evaluation of high-resolution gridded precipitation products over Bhutan (1998-2012). Int. J. Climatol. 2016, 36, 1067-1087.

(C) 2018 by the authors. Licensee MDPI, Basel, Switzerland. This article is an open access article distributed under the terms and conditions of the Creative Commons Attribution (CC BY) license (http:/ / creativecommons.org/licenses/by/4.0/). 